\title{
Heterostructure of binaries II-VI semiconductors ZnTe and ZnSe / III- V (GaAs, InP, GaSb)
}

\author{
A. HAIDOUX, P. TOMASINI, M. MAURIN, J.C. TEDENAC, D. COQUILLAT*, A. RIBAYROL*, \\ J.P. LASCARAY* , D. BOUCHARA*, A. ABOUNADI* , J. CALAS ${ }^{*}$ and B. DUCOURANT ${ }^{* *}$
}

Laboratoire de Physicochimie des Matériaux Solides, URA CNRS 407, Université de Montpellier II, Place E. Bataillon, 34095 Montpellier cedex 05, France

* Groupe d'Etude des Semiconducteurs, URA CNRS 357, Université de Montpellier II, Place E. Bataillon, 34095 Montpellier cedex 05, France

** Laboratoire des Agrégats Moléculaires et des Matériaux Inorganiques, Université de Montpellier II, Place E. Bataillon, 34095 Montpellier cedex 05, France

\begin{abstract}
Epitaxial $\mathrm{ZnSe}, \mathrm{ZnTe}$ and multilayers have been grown on III-V ( InP, GaAs and GaSb ) substrates by organometallic vapor phase epitaxy. First, the OMVPE growth technique used is described. The microstructural quality of the epilayers was determined by SEM (EDX) and $X$-Ray diffraction. Mechanichal strain, due firstly to a mismatch between II-VI layers and III-V substrates and secondly to different thermal expansion coefficients is studied. Reflectivity and photoluminescence spectra are presented for one type of material. Growth parameters are identified and problems associated to experimental conditions are discussed.
\end{abstract}

\section{Introduction}

Zinc selenide and zinc telluride have been considered as promising materials for application in diodes emitting devices because of their direct band gap at room temperature (1). In conjunction with other semiconductors visible lasers, high speed devices and tunable visible detectors could be produced. The main interest now in this research is to obtain low resistivity p-type materials. Low temperature processes to produce II-VI epilayers have been recently investigated : Molecular Beam Epitaxy (2-5), Hot Wall Epitaxy (4) and OrganoMetalic Vapor Phase Epitaxy $(6,7)$. OMVPE is an attractive technique because it is the most suitable for large scale applications ( production as well as high quality epilayer).

For this reason the growth and doping of zinc chalcogenide by OMVPE method should be considered. Moreover, in order to obtain information on the stresses (and associated strains) it is of interest to study the misfit dislocations in the layers. Up to now, gallium arsenide substrates have been the mainly used subtrate for the growth of these semiconductors (8). However epilayer quality is dependent of the lattice-matching and the thermal expansion coefficient difference of the two materials.

This paper presents some results regarding the growth of $\mathrm{ZnSe}$ and $\mathrm{ZnTe}$ on $\mathrm{InP}(001), \mathrm{GaSb}(001)$, GaAs (001) and alternative $\mathrm{ZnSe} / \mathrm{ZnTe} / \mathrm{InP}(001)$ structures. State of strain is studied by means of X-Ray diffraction and optical methods such reflectivity and photoluminescence.

\section{Experiments}

$\mathrm{ZnSe}$ and $\mathrm{ZnTe}$ is grown by OMVPE at atmospheric pressure in horizontal reactor with graphite susceptor heated by a high frequency heater. The reactant carrier gas flow is controlled by an idle / vent / run switching manifold. The flows are switched under pressure balanced conditions. Reactants are transported through the injector tube inside the reactor and gas flows are tangential to the substrate. Dimethylzinc (DMZn), Diethylselenium (DESe) and Diisopropyltelluride (DiPTe) are used as organometallic sources in hydrogen gas flow. Exhaust fluxes are completely destroyed by a chemical process. The DMZn, DESe and DiPTe sources are mainted at $-7,15$ and $40^{\circ} \mathrm{C}$ respectively. The hydrogen gas flux carries 
precursors through bubblers, it is controlled in order to obtain the appropriate partial pressure, given by the relation : $P_{r, i}=P_{i} / P_{T} \cdot d_{r, i} / D_{T}$; where $P_{r, i}$ is the partial pressure of the $i$-precursor, $d_{r, i}$ hydrogen flow that carries the precursor $i$ through the $\mathrm{i}$-bubbler, $\mathrm{P}_{\mathrm{i}}{ }_{\mathrm{i}}$ is the vapor pressure of the $\mathrm{i}$ precursor at $\mathrm{T}_{\mathrm{i}}$ and $P_{\mathrm{T}}, D_{\mathrm{T}}$ are the total pressure and flows in the reactor.

Table I : Growth conditions

$\begin{array}{llllllll} & \mathrm{T}_{\mathrm{G}} & \mathrm{P}_{1} & \mathrm{P}_{2} & \mathrm{P}_{3} & \mathrm{D}_{\mathrm{T}} & \mathrm{V}_{\mathrm{G}} & \mathrm{LM} \\ & \mathrm{C} C & \left(10^{-4} \mathrm{~atm}\right) & \left(10^{-4} \mathrm{~atm}\right) & \left(10^{-4} \mathrm{~atm}\right) & (\mathrm{a} / \mathrm{mm}) & (\mu \mathrm{m} / \mathrm{h}) & (\%) \\ \mathrm{ZnSe/InP}(100) & 530 & 11 & & 5.7 & 2 & 12 & +3.8 \\ \mathrm{ZnTe} / \mathrm{InP}(100) & 340-400 & & 10.7 & 5.7 & 2 & 0.6-2.5 & +4 \\ \mathrm{ZnTe} / \mathrm{GaSb}(100) & 340-400 & & 10.7 & 5.7 & 2 & 0.6-5 & +0.1 \\ \mathrm{ZnTe} / \mathrm{GaAs}(100) & 350-400 & & 10.7 & 5.7 & 2 & 0.6-3.3 & +7\end{array}$

where $\mathrm{T}_{\mathrm{Gi}}$ is the growth temperature, $\mathrm{P}_{1}$ the partial pressure of DESe, $\mathrm{P}_{2}$ the partial pressure of DiPTe, $\mathrm{P}_{3}$ the partial pressure of DMzn, $\mathrm{D}_{\mathrm{T}}$ the hydrogen flux, $\mathrm{V}_{\mathrm{G}}$ the growth rate and $\mathrm{LM}$ is the theoretical lattice mismatch between substrate and layer.

The InP(001), GaSb $(001)$ and $\mathrm{GaAs}(001)$ substrates were cleaned by bromine methanol solution $1.5 \%$, rinsed with methanol, deionised water, and dried with nitrogen. Before running the process, the substrates are then loaded inside the reactor and thermally etched at $550^{\circ} \mathrm{C}$ for ten minutes ; thermal etching is not suitable for InP substrates. Experimental conditions used for growth process of zinc selenide and zinc telluride thin films are listed in table $\mathrm{I}: \mathrm{ZnSe}$ films are made at $530^{\circ} \mathrm{C}$ and $\mathrm{ZnTe}$ films in the temperature range $340^{\circ}-400^{\circ} \mathrm{C}$. In order to improve the crystalline quality of $\mathrm{ZnTe}$ layers, some of them are prepared on ZnTe buffer.

$\mathrm{X}$-Ray characterization was performed using $\mathrm{Cu} \mathrm{K \alpha}$ radiation. $\mathrm{ZnSe}$ epilayers are characterized by a Philips simple diffractometer PW1380 type, with Ni filter or by double crystal X-Ray measurements. ZnTe epilayers are characterized by Siemens diffractometer U 8-006 type, with back monochromator. This study is performed in the $\theta$ range corresponding to (004) crystallographic planes, at room temperature. It enables us to calculate with good precision the lattice parameter. As evidence of the crystalline quality we used the Full Width Half Maximum of the (004) line obtained with back the monochromator and by double crystal X-Ray experiments.

\section{Results}

\section{Microstructural investigations}

Simple X-ray diffraction pattern for two samples of $\mathrm{ZnSe} / \mathrm{InP}$ of $2.2 \mu \mathrm{m}$ and $0.5 \mu \mathrm{m}$ thicknesses are presented in figure $1(\mathrm{a})$ and 1 (b) respectively. In spite of large lattice mismatch $(\varepsilon=+0.035$ for tensile), samples appear to be single layers oriented along the $<001>$ axis. Figure 2 shows an example of good quality of ZnSe epilayers on InP(100) by double crystal X-Ray diffractions and the FWHM is found to be 195 arc sec. This result is in agreament with the other works concerning ZnSe epilayers on GaAs $(8,9)$.

Figure 3 shows the lattice constant versus layer thickness. Below the value of $0.5 \mu \mathrm{m}$, the lattice constant is smaller than the bulk. As the thickness increases, misfit dislocations appear, the strain is released and the layer is relaxed. 


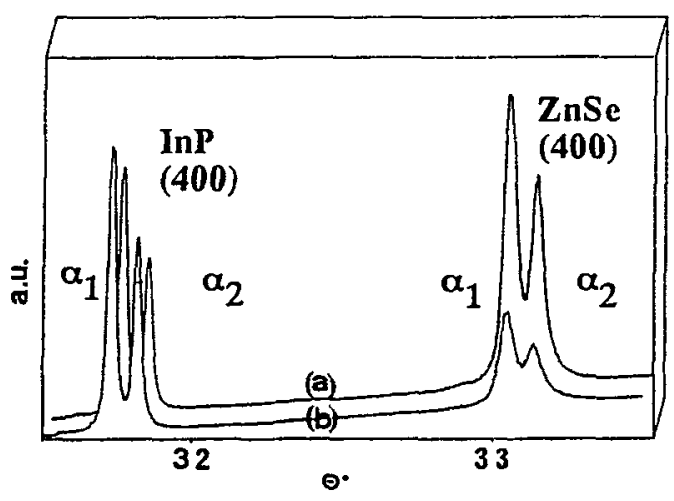

Fig.1(a) and 1(b). - X-ray diffraction pattern of ZnSe epilayer of a $2.2 \mu \mathrm{m}$ and $0.5 \mu \mathrm{m}$ thick respectively grown on InP(001)

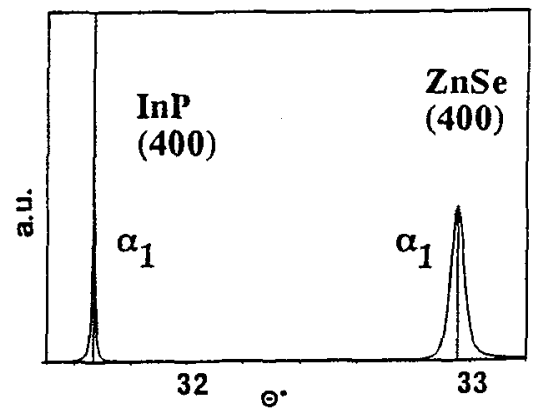

Fig. 2.- DCXD pattern of a $2.0 \mu \mathrm{m}$ thick $\mathrm{ZnSe}$ epilayer grown on InP(001)

$X$-Ray diffraction pattern of a $\mathrm{ZnTe} / \mathrm{InP}(001)$ sample is presented in fig.4(a). The layer was grown at $400^{\circ} \mathrm{C}$ with buffer and arises as single crystalline and oriented along the $<001>$ axis. The FWHM of the $\mathrm{ZnTe}$ line is found to be 104 arc sec suggesting a good crystallinity. The lattice parameter is found to be independent of the layer thickness and not far from the bulk value (fig. 5). This observation indicates the absence of strain in the layer.

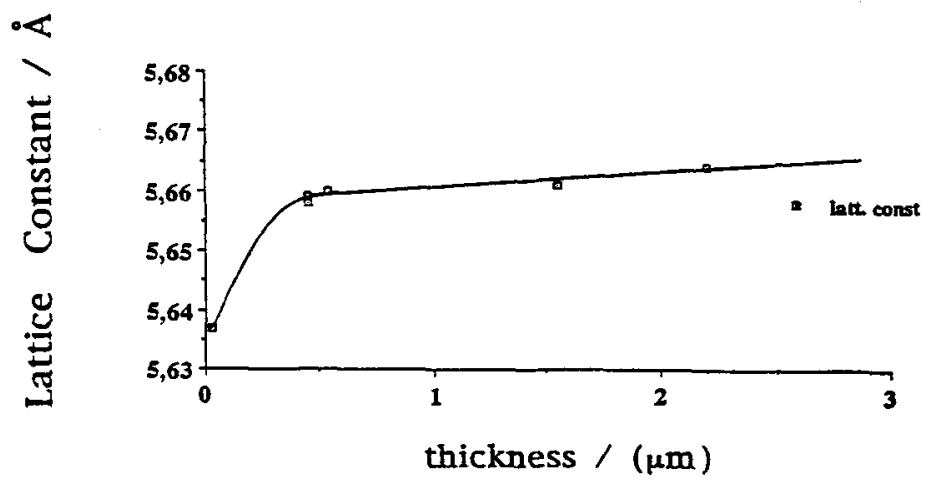

Fig. 3.- Lattice constant vs thickness for $\mathrm{ZnSe}$ epilayer grown on $\operatorname{InP}(001)$. 


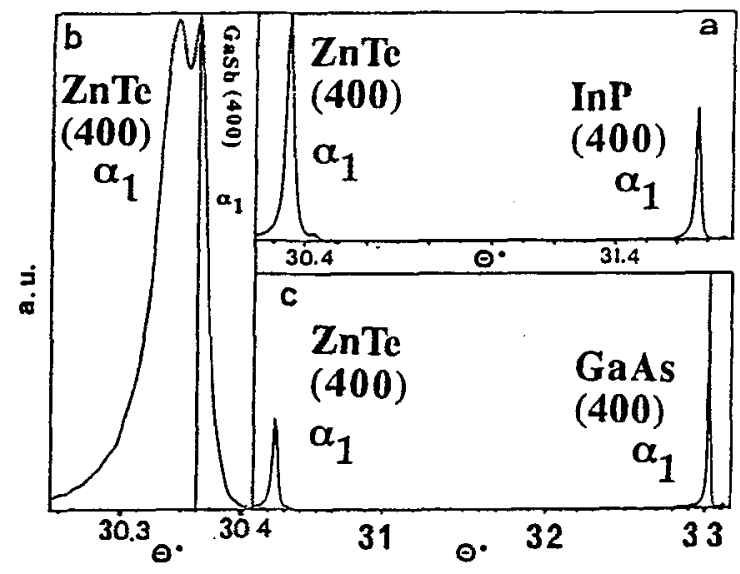

Fig. 4 - X-ray diffraction pattern of $\mathrm{ZnTe}$ epilayers grown on InP substrate (a), GaSb substrate (b), GaAs substrate (c).

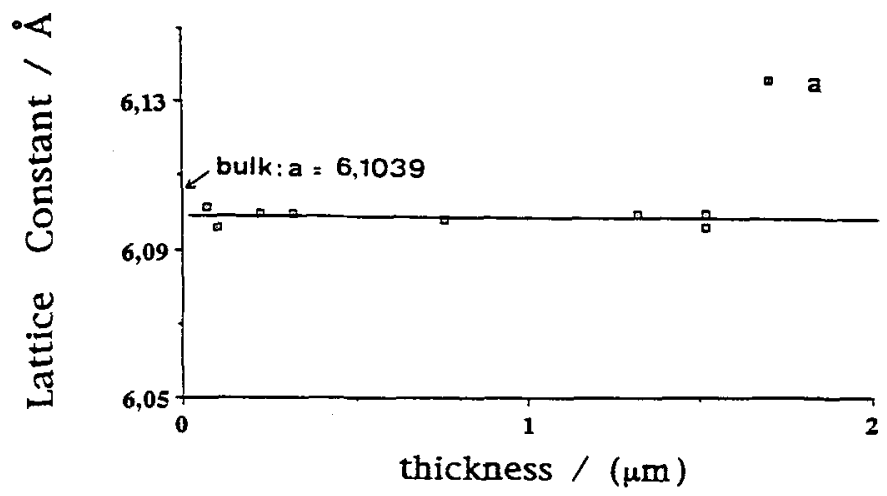

Fig. 5.- lattice constant of $\mathrm{ZnTe}$ epilayer on InP(001) vs thickness.

The growth of $\mathrm{ZnTe}$ epilayers on $\mathrm{GaSb}(100)$ is proved to be more difficult than on InP substrates and needed a good substrate preparation before deposition. Fig. 4(b) shows the diffractogram of one sample performed at $350^{\circ} \mathrm{C}$. This result is in agreement with previous work (10). The lattice constants is measured and is independent of the thickness. This is in contradiction with some work indicating that relaxation of strains in $\mathrm{ZnTe}$ on GaSb is obtained for $4 \mu \mathrm{m}$ thick layers (11).

The same experiment is realized with $\mathrm{GaAs}(001)$. Fig. 4 (c) shows the diffractogram of a sample obtained at $350^{\circ} \mathrm{C}$. Single crystalline layers oriented along (001) planes are successfully grown despite the large mismatch in lattice parameter. The ZnTe diffraction peak has a FWHM of about 150 arcsec.

By SEM observations on zinc telluride epilayers grown on InP, one can observe diamond shaped hillocks with few growth pits in places (Fig.6). We present the surface of $\mathrm{ZnTe} / \mathrm{GaSb}$ in which is possible to observe a rough surface with numerous features oriented along the same direction (fig. 7). This typical morphology of ZnTe layer grown on III-V substrates has already been observed by differents authors $(11,12)$.

Finally a multilayer structure $\mathrm{ZnSe} / \mathrm{ZnTe} / \mathrm{InP}(001)$ is prepared. The fig. 8 shows the X-Ray diffraction pattern corresponding to this structure. Both layers look oriented along the $<001>$ axis with same quality as it has been shown previously. 


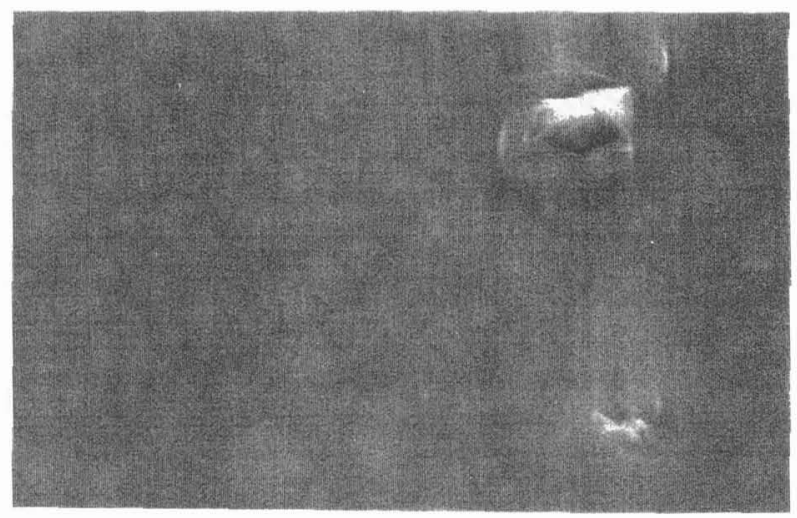

Fig.6.- SEM observation of ZnTe surface of one sample grown on InP without buffer at $380^{\circ} \mathrm{C}$.

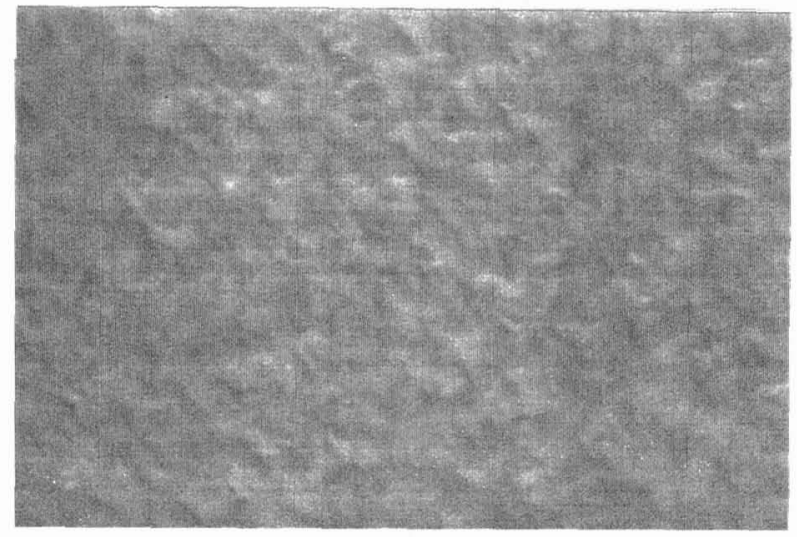

Fig.7.- SEM observation of $\mathrm{ZnTe}$ surface of one sample grown on GaSb without buffer at $340^{\circ} \mathrm{C}$.

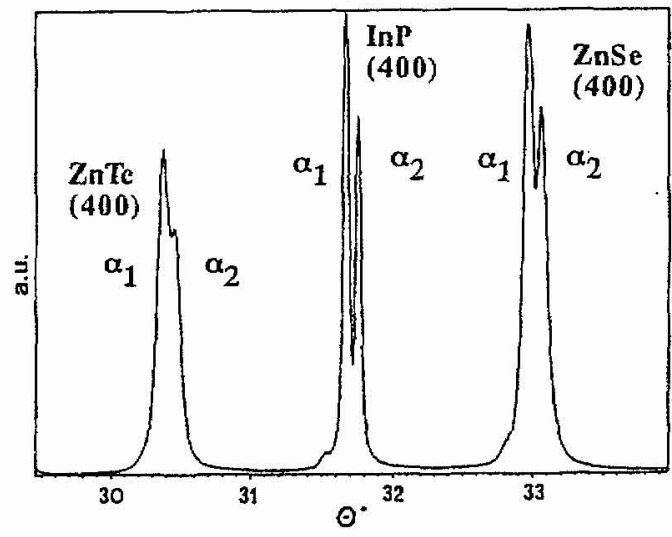

Fig. 8.- X-Ray diffraction pattern of $\mathrm{ZnSe} / \mathrm{ZnTe}$ alternative epilayer on InP(100) using the same deposition conditions. 


\section{Reflectivity and Photoluminescence measurements}

Among the prepared samples we focused our physical work in a first step on $\mathrm{ZnSe} / \mathrm{nP}$ layers. In the zinc blende structure, it is well known the strain due to lattice mismatch is given by equation (1):

$$
\text { (1) } \varepsilon=\varepsilon_{\mathrm{xx}}=\varepsilon_{\mathrm{yy}}=\left(\mathrm{a}-\mathrm{a}_{\mathrm{ZnSe}}\right) / \mathrm{a}_{\mathrm{ZnSe}}
$$

where $\boldsymbol{\varepsilon}$ is defined as negative (or positive) for compressive (or tensile ) strain, a $\mathbf{Z n S e}_{\mathbf{n}}$ and a are lattice constant of bulk ZnSe and that of epilayer along the layer surface, respectively. The energy splitting between the heavily and light hole bands is given by

$$
\text { (2) } \Delta \mathrm{E}_{\mathrm{S}}=\Delta \mathrm{E}_{\mathrm{hh}}-\Delta \mathrm{E}_{\mathrm{lh}}=5.117 \varepsilon(\mathrm{meV})
$$

The experimental values of splitting of excitonic transitions $\Delta \mathrm{E}_{\mathrm{S}}$ and the calculated values of strain from (1) are listed in table II as a function of thickness. For an hypothetical pseudomorphic epilayer (one or few epilayers) the epilayer is under tensile strain and the mismatch splitting would be $\Delta \mathrm{E}_{\mathrm{ps}}=180 \mathrm{meV}$. For fully relaxed structure the splitting is due to thermoelastic strain. At $4.2 \mathrm{~K}$ the value of thermoelastic strain is $\varepsilon_{\mathrm{th}}=0.0029(15,17)$. The epilayer is also in tensile strain and the corresponding splitting is equal to 15 (meV). For all the epilayers investigated with reflectivity measurements (fig. 9) the values of splitting are closed to $\Delta \mathrm{E}_{\mathrm{th}}$. with a smaller value. Such a behavior reveals that epilayers are fully relaxed and that the thermoelastic strain is released by two dimentionnal stress of the substrate at the interface or to bending of the substrate $(18,19)$.

Table II : value of the energy splitting between the heavy $E_{h h}$ and light $E_{l h}$ hole bands and value of strain as a function of thickness

$\begin{array}{lllll}\text { thickness } & \Delta \mathrm{E}_{\mathrm{hh}} & \Delta \mathrm{E}_{\mathrm{lh}} & \Delta \mathrm{E}_{\mathrm{S}} & \varepsilon \\ (\mu \mathrm{m}) & (\mathrm{eV}) & (\mathrm{eV}) & (\mathrm{meV}) & \left(10^{-3}\right) \\ 0.45 & 2.8003 & 2.7885 & 11.8 & 60 \\ 0.50 & 2.8005 & 2.7899 & 10.6 & 54 \\ 1.55 & 2.8001 & 2.7914 & 8.7 & 44 \\ 2.2 & 2.8020 & 2.7950 & 7.0 & 35\end{array}$

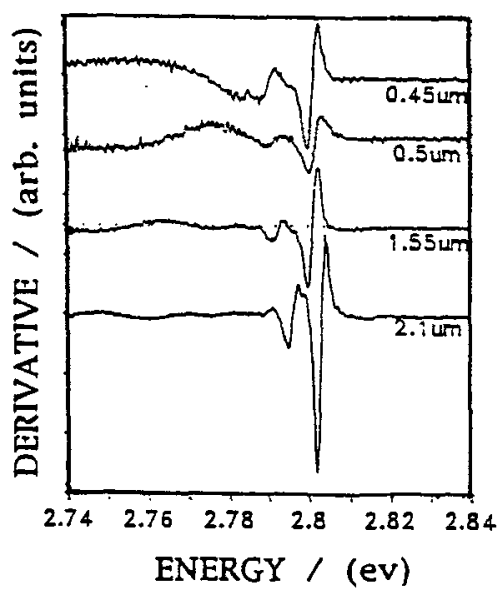

Fig.9.- Derivative curve of reflectivity spectra at $4.2 \mathrm{~K}$ of $\mathrm{ZnSe}$ epilayers grown on InP(001) for different thickness above the band-gap edge. The minima correspond to energy transition. 
Table III and fig. 10 presents the different results of luminescence measurements. Near the band edge, $I_{2}$ peak, usually attributed to a donor-bound-exciton $(20,21)$ the chemical nature of which is not clear, was observed. This peak is not very intense in those samples. $\mathrm{ZnSe} / \mathrm{GaAs}$ studies show that this peak is higher for lower growth temperature (21).

Table III : list of assigned PL transitions at 4.2K in $\mathrm{ZnSe}$ layers grown on (100) InP versus layer thickness

\begin{tabular}{|c|c|c|c|c|c|}
\hline thickness & $I_{2}$ & $\mathrm{I}_{2}$ & $\mathbf{I}_{1}$ & $\mathrm{I}_{\mathrm{v}}$ & DAP \\
\hline$(\mu \mathrm{m})$ & & & & & \\
\hline 2.1 & 2.794 & 2.789 & & 2.776 & \\
\hline 1.55 & & 2.789 & 2.785 & 2.777 & 2.684 \\
\hline 0.50 & & 2.789 & & & 2.684 \\
\hline 0.45 & & 2.789 & 2.784 & 2.771 & 2.685 \\
\hline
\end{tabular}

$\mathrm{I}_{2}$ was also noticed in $2.1 \mu \mathrm{m}$ thickness epilayers, wich is either due to an excited state of $\mathrm{I}_{2}$ or a strain effect on $\mathrm{I}_{2} . \mathrm{I}_{1}$ peak was seen in $0.45 \mu \mathrm{m}$-thick and $1.55 \mu \mathrm{m}$-thickepilayer. It is usually interpreted as an acceptor bound exciton. The presence at the same time of donors and acceptors is confirmed in most samples by donor to acceptor transition peak (DAP), at the same position observed in ZnSe/GaAs layers, this DAP is followed by a group of phonon replica, separated by $31 \mathrm{MeV}$. A $\mathrm{L}_{\mathrm{V}}$ (22) peak at $2.77 \mathrm{eV}$ due to vacancy bound exciton was a recurent feature in our epilayers. Such a peak is characteristic of high temperature grown samples (at 4009 in $\mathrm{ZnSe} / \mathrm{GaAs}$. It disappears at lower temperature. At a longer distance from the band edge, samples presents some " $\mathrm{Cu}$ green" band around $2.220 \mathrm{eV}$ and shallow acceptors around $1.940 \mathrm{eV}$.

Luminescence experiments show an important compensation factor in the epilayers, wich is reaveled by DAP. The presence of vacancies is another defect deduced from the $\mathrm{I}_{\mathrm{v}}$ peak. This work is presently in progress.

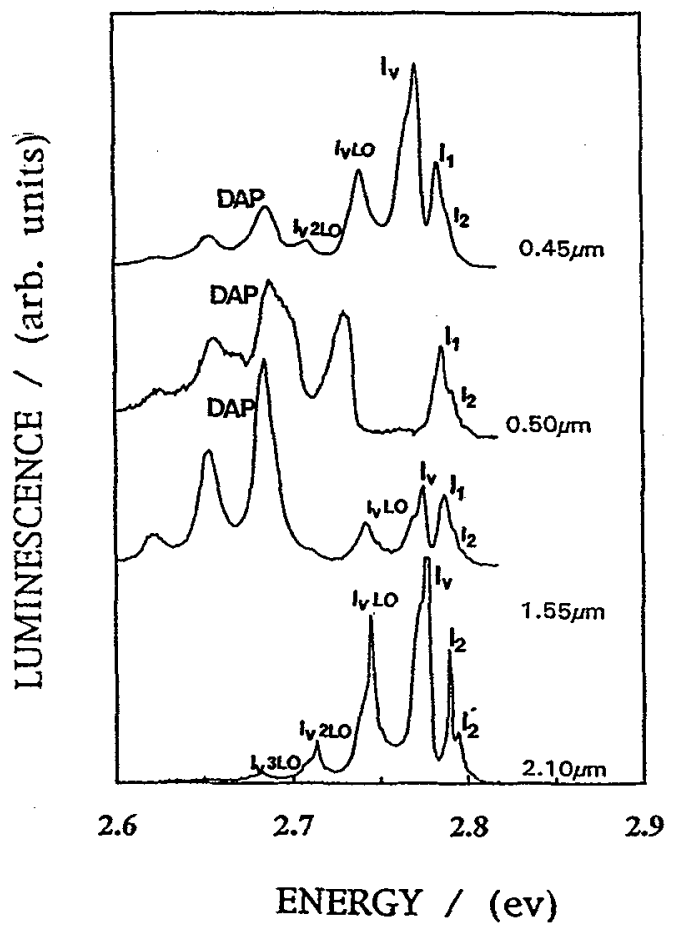

Fig.10.- Photoluminescence spectra of $\mathrm{ZnSe}$ epilayers at $4.2 \mathrm{~K}$ for different thickness 


\section{Conclusion}

Using OMVPE technique we performed a large serie of $\mathrm{ZnSe}, \mathrm{ZnTe}$ thin film samples on various III-V substrates. In order to retermine experimental conditions for obtaining such structures as ZnSe/ZnTe and $\mathrm{ZnSe} Z \mathrm{ZnSe}_{1-\mathrm{x}} \mathrm{Te}_{\mathrm{x}}$ we have studied the microstructural quality of the layers obtained. By means of XRay analysis we have confirmed the good quality of the samples. Moreover for the structure $\mathrm{ZnSe/ZnTe/InP} \mathrm{X-Ray} \mathrm{studies} \mathrm{has} \mathrm{not} \mathrm{revealed} \mathrm{gradient} \mathrm{concentration} \mathrm{at} \mathrm{the} \mathrm{interface} \mathrm{and} \mathrm{it} \mathrm{is} \mathrm{an} \mathrm{indication}$ for a steep interface. There systems are currently under examination using SIMS and ESCA.

\section{References}

(1) GUNSHOR R., NURMIKKO A., KOYABASHI M., Physics World, vol. 5, n 3 ( 1992) 46

(2) GUTOWSKI J., Semicond. Sci. Tech. 6(1991) A51

(3) SI DANG, CIBERT J., GOBIL A., SAMINADAYER K., TATARENKO S., Appl. Phys. Let. 55 (1989) 235

(4) KUDLEK G., PRESSER N., GUTOWSKI J., HINGERL K., SITTER H., DURBIN S. M., MEULEC D.R., KOYABASHI K. GUNSHOR R. L., J. Appl. Phys. 68 (1991) 5630

(5) WILSON B.A., BONNER C.E., FELDMAN R.D., AUSTIN R.F., KISKER D.W., KRAYENSKI J.J., J. Appl. Physics, 64 (1988) 3210

(6) WAGNER H.P., KHUN W. and GEBHART W., J. Crystal Growth, 101 (1990) 199

(7) EKAWA M., TAGASHI T., Jap. J. Appl. Phys. 28 (1989) L1341

(8) WRIGHT P.J., COKAYNE B., PARBROOK P.J., JONES A.C., O'BRIEN P. and WALSH, J. Crystal Growth, 104 (1990) 601

(9) STOHER M., MAURIN M., BARBUSSE D., FOURCADE R., Eur. J. Solid State Inorg. Chem., 29 (1992) 1145

(12) TOMPA G.S., SUMMERS C.J., J. Vac. Sci. Technol., A 10-4-(1992) 903

(11) ABRAMOF E., HINGERL K., PESEK A., SITTER H., Semicond. Sci. Technol., 6 (1991) A80

(10) SHTRIKMAN H., RAIZMAN A. ORON M., EGER D., J. Crystal Growth 88 (1988) 522

(13) LEE B. H., J. Appl. Physics, 41 (1970) 2984

(14) ROCKWELL B., CHANDRASEKHAR H.R., CHANDRASEKHAR M., RAMDAS A.K., KOBAYASHI M., GUNSHOR R.L., Phys. Rev. B44 (1991) 11307

(15) KUDMAN I, PAFF R. J., J. Appl. Phys., 43 (1972)3760

(16) SMITH T. F., WHITE G.K., J. Phys. C : Solid State Phys. 8 (1975) 2031

(17) HARUNA K., MAETA H.,OHASHI K., KOIKE T., J. Phys. C : Solid State Phys. 20 (1987) 5275

(18) STOEHR M., HAMDANI F., LASCARAY J.P, MAURIN M., Phys. Rev. B,vol.44 n 16 (1991)-II 8912

(19) COQUILLAT D.and all, to be published

(20) DEAN P. J., Phys. Rev. vol.78 n³ (1969) 1310

(21) KUDLEK G., PRESSER N.,GUTOWSKI J., DURBIN S., MENKE D., KOBAYASHI M., GUNSHOR R.L., Proceedings of the Fourth International Conference of II-VI Compounds, Berlin, J. Cryst. Growth, 101 (1990) 667

(22) BOUZAMA A., YATES H.M., JAMES L., PATTERSON I.A., COLE-HAMILTON D.J., WILLIAMS J.O., J. de Physique IV, supl.JP II, vol.1,Sept. (1991) C2-945 